\title{
Impact of an endurance training program on exercise-induced cardiac
}

\section{biomarker release}

\author{
Alejandro Legaz-Arrese, ${ }^{1}$ Isaac López-Laval, ${ }^{1}$ Keith George, ${ }^{2}$ Juan José Puente-Lanzarote, ${ }^{3}$ \\ Carmen Mayolas-Pi, ${ }^{1}$ Enrique Serrano-Ostáriz, ${ }^{1}$ Pablo Revilla-Martí, ${ }^{3}$ Diego Moliner-Urdiales, ${ }^{4}$ \\ and Joaquín Reverter-Masià ${ }^{5}$ \\ ${ }^{1}$ Section of Physical Education and Sports, University of Zaragoza, Zaragoza, Spain; ${ }^{2}$ Resarch Institute for Sport and \\ Exercise Sciences, Liverpool John Moores University, Liverpool, United Kingdom; ${ }^{3}$ Lozano Blesa University Hospital, \\ Zaragoza, Spain; ${ }^{4}$ Department of Education, University Jaume I, Castellón, Spain; and ${ }^{5}$ Research Group Human Movement, \\ University of Lleida, LLeida, Spain
}

Submitted 22 December 2014; accepted in final form 5 February 2015

Legaz-Arrese A, López-Laval I, George K, Puente-Lanzarote JJ, Mayolas-Pi C, Serrano-Ostáriz E, Revilla-Martí P, MolinerUrdiales D, Reverter-Masià $\mathbf{J}$. Impact of an endurance training program on exercise-induced cardiac biomarker release. Am J Physiol Heart Circ Physiol 308: H000-H000, 2015. First published doi:10.1152/ajpheart.00914.2014.-We

evaluated the influence of a 14-wk endurance running program on the exercise-induced release of high-sensitivity cardiac troponin $\mathrm{T}$ (hs$\mathrm{cTnT}$ ) and $\mathrm{NH}_{2}$-terminal pro-brain natriuretic peptide (NT-proBNP). Fifty-eight untrained participants were randomized to supervised endurance exercise (14 wk, 3-4 days/wk, 120-240 min/wk, 65-85\% of maximum heart rate) or a control group. At baseline and after the training program, hs-cTnT and NT-proBNP were assessed before and $5 \mathrm{~min}, 1 \mathrm{~h}, 3 \mathrm{~h}, 6 \mathrm{~h}, 12 \mathrm{~h}$, and $24 \mathrm{~h}$ after a 60 -min maximal running test. Before training, hs-cTnT was significantly elevated in both groups with acute exercise $(P<0.0001)$ with no between-group differences. There was considerable heterogeneity in peak hs-cTnT concentration with the upper reference limit exceeded in $71 \%$ of the exercise tests. After training, both baseline and postexercise hs-cTnT were significantly higher compared with pretraining and the response of the control group $(P=0.008)$. Acute exercise led to a small but significant increase in NT-proBNP, but this was not mediated by training $(P=0.121)$. In summary, a controlled endurance training intervention resulted in higher pre- and postexercise values of hscTnT with no changes in NT-proBNP.

high-sensitivity cardiac troponin $\mathrm{T}$; $\mathrm{NH}_{2}$-terminal pro-brain natriuretic peptide; exercise; endurance training

EXERCISE promotes the elevation of serum troponins [cardiac troponin I (cTnI) and cardiac troponin $\mathrm{T}(\mathrm{cTnT})]$ and $\mathrm{NH}_{2-}$ terminal pro-BNP (NT-proBNP), which are accepted parameters for the identification of cardiac damage and dysfunction. Postexercise values of these biomarkers are often higher than the population's upper reference limit (URL) $(27,30)$.

The clinical significance of the increase in cardiac-specific biomarkers after exercise in healthy subjects is unclear. Consequently, it is of interest to determine what personal or environmental factors mediate the exercise-induced release of cardiac biomarkers. One specific issue of interest has been the importance of training status. To date, cross-sectional studies have been inconsistent. Neilan et al. (20) reported higher values for cTnT and NT-proBNP in less well-trained runners after a marathon, and this has been supported by others $(5,15$,

\footnotetext{
Address for reprint requests and other correspondence: A. Legaz-Arrese, Departamento de Fisiatría y Enfermería, C/Domingo Miral S/N, Zaragoza
} 50009, Spain (e-mail: alegaz@unizar.es).
19, 21, 39). Conversely, others have found no association between training status and biomarker release $(4,9,27,30,38)$, and recent controlled and field-based studies have even suggested higher values of high-sensitivity (hs-)cTnT in those with high levels of training (Legaz-Arrese et al., unpublished observations, and Ref. 24). Data for NT-proBNP are also equivocal with respect to training status $(8,25,27,30,38)$.

These discrepancies may be largely based on the limitations associated with cross-sectional studies and the lack of control in field-based competitive studies as well as the number and timing of blood draws postexercise. To date, there are no longitudinal training interventions that have assessed exerciseinduced cardiac biomarker release before and after an intervention. Consequently, we used a randomized, controlled trial to investigate the effects of a 14-wk endurance running training program compared with a control group with no intervention on the release of hs-cTnT and NT-proBNP consequent to a 60 -min running time trial. We hypothesized that training would have no significant effect on the exercise-induced release of cardiac biomarkers.

\section{METHODS}

Participants and design. An invitation to participate in the study was sent to men and women $(n=323)$ between 18 and $45 \mathrm{yr}$ of age from two university faculties and a local company (Fig. 1). Sixty-nine F1 potentially eligible participants responded and requested more information, and all provided written informed consent after the protocol was explained to them. The Committee on Biomedical Ethics of the Aragon Government approved the present study.

Exclusion criteria were a significant personal or early family history of cardiovascular disease and/or abnormal ECG at baseline examination. Furthermore, we excluded those already pursuing vigorous levels of physical activity according to the self-administered, long format of the International Physical Activity Questionnaire (IPAQ) (3). The Spanish version (22) of the revised Physical Activity Readiness Questionnaire (35) was also administered to identify persons at risk for adverse events while exercising. Overall, 11 participants were excluded from the study because they performed vigorous physical activity on a regular basis according to the IPAQ, and the remaining 58 participants were randomly assigned to either a training group or a control group according to a computer-generated randomization list (ratio of 1.5:1). Seven participants in the training group (3 participants did not complete the exercise test and 4 participants did not attend $<90 \%$ of training sessions) and 5 participants in the control group ( 2 participants did not complete the exercise test and 3 participants did not complete blood sampling) were not included in the final analysis. At the completion of the study, 28 subjects from the training 
Fig. 1. The flow of participants throughout the trial.

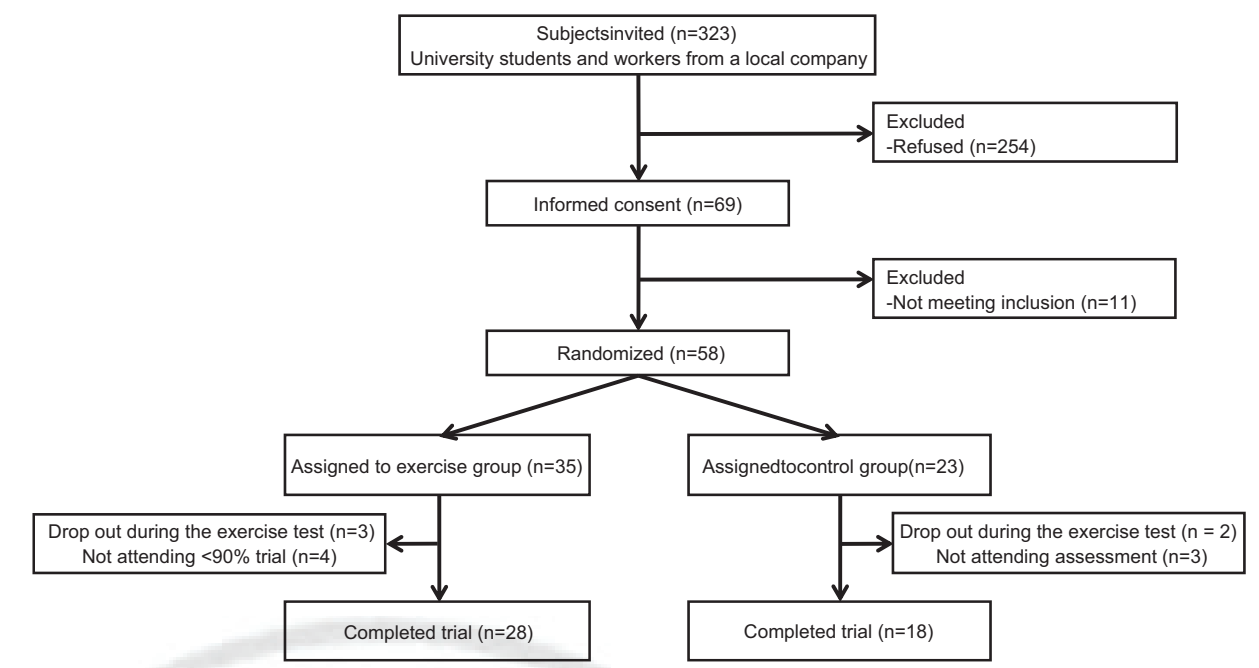

group (22 men and 6 women) and 18 subjects from the control group (14 men and 4 women) were included in the intervention analysis.

Experimental procedures. All measurements were taken by examiners blinded to group assignment. During the first laboratory visit, subjects underwent anthropometric assessment. Body height was measured to the nearest $0.1 \mathrm{~cm}$ (SECA 225, SECA, Hamburg, Germany). Body mass was determined to the nearest $0.05 \mathrm{~kg}$ (SECA 861, SECA). Skinfold thickness was measured at the triceps, subscapular, supraspinal, abdominal, and front thigh and medial calf locations using Holtain skinfold callipers (Holtain, Crosswell, Crymych, UK). The fat percentage was obtained by the equation of Yuhasz (41).

On the second and third visit to the laboratory, two exercise sessions of 30- and 45-min duration were performed to accustom subjects to running and pacing exercise intensity on a treadmill. Participants refrained from strenuous exercise for $48 \mathrm{~h}$ before the fourth laboratory visit, during which they performed a 60-min "allout" running "time trial" on a treadmill (Run Exicite 700, Technogym, Italia). The same "resting" period was established posttraining. Before the test, subjects completed a self-paced 5-min warmup [heart rate $(\mathrm{HR})<130$ beats/min). Pairs of subjects competed side by side to provide some motivation and competition, and strong verbal encouragement was provided during the test. Subjects were constantly aware of the time and distance covered. Water intake was allowed ad libitum. HR was recorded continuously during the tests via a Polar HR monitor (Polar Electro Oy, Kempele, Finland). The distance run in each test was recorded every 10 min. Pacing strategy was defined as the mean running velocity every $10 \mathrm{~min}$. Immediately afterward, test participants rated the test for perceived exertion (1). Venous blood samples were taken before, immediately after (5 min), and 1, 3, 6, 12, and $24 \mathrm{~h}$ after exercise to assess serum hs-cTnT and NT-proBNP. All testing sessions occurred at 11:00 AM in an air-conditioned laboratory with the temperature and relative humidity set at $20^{\circ} \mathrm{C}$ and $50 \%$, respectively.

Exercise training. The 14-wk endurance training program followed a periodized progressive traditional design (10) consisting of five mesocycles with the program divided into three training periods (Table 1). Briefly, in the preparatory period, the frequency and $\mathbf{T}$ duration of training were increased and the intensity remained the same. In the first mesocycle of the competitive period, the duration and intensity were increased. The intensity continued to increase in the second mesocycle of this period, with a progressive decrease in the duration. In the taper period, the intensity was kept the same and the duration was decreased. In all sessions, continuous running was performed on a flat course. From the second to fifth mesocycle, sessions of higher and lower demand were rotated each week. Furthermore, regular stretching, core strengthening exercises, and running drills were included in the sessions to minimize injury risk and improve running technique. Participants were provided with HR monitors. During each training session, intensities were individualized by prescribing training paces based on the percent maximal HR $\left(\% \mathrm{HR}_{\max }\right)$ according to different work areas (29). Each session was allowed a variation of $\pm 3 \%$ of the $\% \mathrm{HR}_{\max }$ prescribed. All sessions

Table 1. Characteristics of the training program

\begin{tabular}{|c|c|c|c|c|c|c|c|c|}
\hline Period & Mesocycle & Week & $\begin{array}{c}\text { Session 1, } \\
\text { min-\%HR } \max \end{array}$ & $\begin{array}{c}\text { Session } 2, \\
\text { min-\% } \mathrm{HR}_{\max }\end{array}$ & $\begin{array}{c}\text { Session 3, } \\
\text { min-\%HR } \max \end{array}$ & $\begin{array}{c}\text { Session } 4, \\
\text { min-\%HR } \max \end{array}$ & $\begin{array}{l}\text { Duration/Week, } \\
\min \end{array}$ & $\begin{array}{c}\text { Intensity/Week, } \\
\% \mathrm{HR}_{\max }\end{array}$ \\
\hline \multirow[t]{6}{*}{ Preparatory } & 1 & 1 & $40 \min -65 \%$ & $40 \min -65 \%$ & $40 \min -65 \%$ & & 120 & 65 \\
\hline & & 2 & $40 \min -65 \%$ & $40 \min -65 \%$ & $40 \min -65 \%$ & & 120 & 65 \\
\hline & & 3 & $50 \mathrm{~min}-65 \%$ & $50 \mathrm{~min}-65 \%$ & $50 \min -65 \%$ & & 150 & 65 \\
\hline & & 4 & $50 \mathrm{~min}-65 \%$ & $50 \mathrm{~min}-65 \%$ & $50 \mathrm{~min}-65 \%$ & & 150 & 65 \\
\hline & 2 & 5 & $50 \mathrm{~min}-65 \%$ & $40 \min -65 \%$ & $50 \mathrm{~min}-65 \%$ & $40 \min -65 \%$ & 180 & 65 \\
\hline & & 6 & $50 \min -65 \%$ & $40 \min -65 \%$ & $50 \mathrm{~min}-65 \%$ & $40 \min -65 \%$ & 180 & 65 \\
\hline \multirow[t]{6}{*}{ Competition } & 3 & 7 & $60 \mathrm{~min}-70 \%$ & $40 \min -65 \%$ & $60 \mathrm{~min}-70 \%$ & $40 \min -65 \%$ & 200 & $65-70$ \\
\hline & & 8 & $60 \mathrm{~min}-70 \%$ & $40 \min -65 \%$ & $60 \mathrm{~min}-70 \%$ & $40 \min -65 \%$ & 200 & $65-70$ \\
\hline & & 9 & $70 \mathrm{~min}-75 \%$ & $40 \mathrm{~min}-70 \%$ & $70 \mathrm{~min}-75 \%$ & $40 \mathrm{~min}-70 \%$ & 220 & $70-75$ \\
\hline & & 10 & $80 \mathrm{~min}-75 \%$ & $40 \mathrm{~min}-70 \%$ & $80 \mathrm{~min}-75 \%$ & $40 \min -70 \%$ & 240 & $70-75$ \\
\hline & 4 & 11 & $70 \mathrm{~min}-80 \%$ & $40 \mathrm{~min}-75 \%$ & $70 \mathrm{~min}-80 \%$ & $40 \min -75 \%$ & 220 & $75-80$ \\
\hline & & 12 & $60 \mathrm{~min}-85 \%$ & $40 \mathrm{~min}-80 \%$ & $60 \mathrm{~min}-85 \%$ & $40 \min -80 \%$ & 200 & $80-85$ \\
\hline \multirow[t]{2}{*}{ Taper } & 5 & 13 & $50 \min -85 \%$ & $40 \min -80 \%$ & $50 \min -85 \%$ & $40 \min -80 \%$ & 180 & $80-85$ \\
\hline & & 14 & $40 \mathrm{~min}-85 \%$ & $40 \mathrm{~min}-80 \%$ & $40 \min -85 \%$ & $40 \mathrm{~min}-80 \%$ & 160 & $80-85$ \\
\hline
\end{tabular}

$\% \mathrm{HR}_{\max }$, percent maximal heart rate (HR). 
were conducted in groups and were supervised by a coach. The control group was instructed not to change their habits regarding physical activities during the period, and no subject performed vigorous levels of physical activity according to the IPAQ.

Blood sampling procedures. Blood samples were drawn by repetitive venipuncture from an antecubital vein and quickly centrifuged. Serum and plasma were drawn off and stored at $-80^{\circ} \mathrm{C}$ for later analysis. hs-cTnT was measured quantitatively with a new highsensitivity enzyme immunoassay based on electrochemiluminescence technology using a Cobas E 601 analyzer (Roche Diagnostics, Penzberg, Germany). This assay has a range from 3 to $10,000 \mathrm{ng} / \mathrm{l}$ with a lower limit of the blank of $3 \mathrm{ng} / \mathrm{l}$. The coefficient of variation at a mean hs-cTnT level of $13.5 \mathrm{ng} / \mathrm{l}$ is $5.2 \%$. The upper reference limit for hs-cTnT, defined as the 99th percentile of healthy participants, was 14 $\mathrm{ng} / \mathrm{l}$ (7). NT-proBNP was analyzed in serum with an Elecsys proBNP electrochemiluminescent immunoassay on a Roche Elecsys 1010 (Roche Diagnostics, Lewes, UK) with an analytic range of 5-35,000 $\mathrm{ng} / \mathrm{l}$ and intra- and interassay imprecisions of $0.7-1.6 \%$ and 5.3 $6.6 \%$, respectively (2). The URL for NT-proBNP was considered to be $125 \mathrm{ng} / \mathrm{l}$ (34).

Statistical analysis. Statistical analyses were performed using the IBM Statistical Package for the Social Sciences (IBM SPSS Statistics, version 20.0 for Windows). Cohort data are presented as means \pm SD unless otherwise stated. Kolmogorov-Smirnov tests were used to check for normal distribution, and data for cTnI and NT-proBNP were $\log$ transformed before statistical testing. Three-way ANOVA was conducted with two within-subject factors [factor 1: blood sampling time (preexercise and $5 \mathrm{~min}, 1,3,6,12$, and $24 \mathrm{~h}$ postexercise) and factor 2: training status (pre vs. post)] and one between-subject factor (group: control vs. training). Post hoc Bonferroni tests were used when appropriate. To support this analysis, we performed two-way ANOVAs on peak postexercise hs-cTnT and peak NT-proBNP. Finally, for each participant in each trial, we calculated a change score for both biomarkers from preexercise to peak postexercise.

The association between the exercise increase in both biomarkers and other relevant variables (e.g., baseline biomarker concentration, mean HR, and maximal exercise $\mathrm{HR}$ ) were assessed using bivariate Pearson's product-moment correlation coefficients. Differences were considered significant if $P<0.05$.

\section{RESULTS}

Impact of exercise training on subject characteristics and exercise data. No between-group differences existed at baseline, so the groups were well matched at entry (Table 2). The training program led to a decrease in weight and percent fat $(P<0.0001)$. After training, despite the rate of perceived exertion being unchanged, there was an increase in speed in the 60 -min running time trial (range: $1-2.70 \mathrm{~km} / \mathrm{h}, P<0.0001$ ) as well as an increase in mean $\mathrm{HR}$ and $\% \mathrm{HR}_{\max }$. No change in these variables was noted in the control group. Pacing strategy was similar in all subjects and was not influenced by the training program.

Impact of exercise training on hs-cTnT release. A significant main effect of sampling time was observed for hs-cTnT, with increases compared with preexercise at $5 \mathrm{~min}, 1 \mathrm{~h}, 3 \mathrm{~h}, 6 \mathrm{~h}, 12$ h, and $24 \mathrm{~h}$ postexercise $(P<0.0001$; Table 3 and Fig. 2$)$. hs-cTnT was above the URL in $80 \%$ of participants. In most exercise tests, the maximum postexercise value was observed at $3 \mathrm{~h}(83 \%)$ or $6 \mathrm{~h}(13 \%)$, and this was largely consistent preand posttraining. Before the training program, the two groups had similar preexercise [median: $30 \mathrm{ng} / \mathrm{l}$ (range: $3.0-8.1 \mathrm{ng} / \mathrm{l}$ ) in the control group and median: $3.6 \mathrm{ng} / \mathrm{l}$ (range: $3.0-16.2 \mathrm{ng} / \mathrm{l}$ ) in the training group, $P=0.072]$ and peak postexercise hs-cTnT levels [median: $14.7 \mathrm{ng} / \mathrm{l}$ (range: $9.7-65.0 \mathrm{ng} / \mathrm{l}$ ) in the control group and median: $16.6 \mathrm{ng} / \mathrm{l}$ (range: $4.9-140.7 \mathrm{ng} / \mathrm{l}$ ) in the training group, $P=0.919$ ]. A significant group $\times$ training interaction was observed $(P=0.008)$, but no significant interaction between sampling time $\times$ training $\times$ group was found $(P=0.125)$. A significant training $\times$ group interaction was also observed for peak postexercise hs-cTnT $(P=0.002)$. After training, hs-cTnT was lower in the control group at both preexercise [median: $3.2 \mathrm{ng} / \mathrm{l}$ (range: $3.0-7.5 \mathrm{ng} / \mathrm{l}$ ) in the control group and median: $5.1 \mathrm{ng} / \mathrm{l}$ (range: $3.0-16.8 \mathrm{ng} / \mathrm{l}$ ) in the training group, $P=0.016$ ] and peak postexercise [median: $17.8 \mathrm{ng} / \mathrm{l}$ (range: $8.4-49.8 \mathrm{ng} / \mathrm{l}$ ) in the control group and median: $27.7 \mathrm{ng} / \mathrm{l}$ (range: $6.6-171.0 \mathrm{ng} / \mathrm{l}$ ) in the training group, $P=0.007]$.

Peak postexercise hs-cTnT was weakly associated with preexercise hs-cTnT only when all exercise tests were combined $(r=0.358, P<0.0001)$. In the training group, the change in preexercise to peak postexercise hs-cTnT were not associated with changes in 60-min time trial speed $(r=-0.290, P=$ $0.886)$ or changes in mean HR $(r=0.079, P=0.689)$. In the control group, a significant positive association was noted between preexercise and peak postexercise hs-cTnT obtained at the two running time trials $(r=0.610, P=0.007$; and $r=$ $0.742, P<0.0001$ ), suggesting some consistency/reliability in baseline and exercise hs-cTnT response. Interestingly, despite intervention-related changes in preexercise and peak postexercise hs-cTnT in the training group, the between-test correlation for baseline and peak postexercise hs-cTnT were also significant $(r=0.585, P=0.001$; and $r=0.608, P=0.001)$.

Table 2. Subject characteristics and exercise data pre- and posttraining

\begin{tabular}{|c|c|c|c|c|}
\hline & \multicolumn{2}{|c|}{ Control Group $(n=18)$} & \multicolumn{2}{|c|}{ Exercise Group $(n=28)$} \\
\hline & Pretraining & Posttraining & Pretraining & Posttraining \\
\hline \multicolumn{5}{|l|}{ Subject characteristics } \\
\hline Age, yr & $30.6 \pm 8.7$ & & $29.9 \pm 9.9$ & \\
\hline Height, m & $1.76 \pm 0.09$ & & $1.76 \pm 0.06$ & \\
\hline Weight, kg & $69.9 \pm 9.4$ & $69.1 \pm 9.8^{*}$ & $71.1 \pm 8.2$ & $67.9 \pm 8.5^{* \dagger}$ \\
\hline Body fat, \% & $11.6 \pm 4.6$ & $11.1 \pm 4.8^{*}$ & $11.8 \pm 4.4$ & $9.9 \pm 4.4 * \dagger$ \\
\hline Maximum HR, beats/min & $187 \pm 11$ & $187 \pm 11$ & $189 \pm 8$ & $188 \pm 8$ \\
\hline \multicolumn{5}{|l|}{ 60-min performance } \\
\hline Velocity, $\mathrm{km} / \mathrm{h}$ & $10.5 \pm 1.1$ & $10.7 \pm 0.9$ & $10.4 \pm 1.1$ & $12.1 \pm 0.9 * \dagger$ \\
\hline Mean HR, beats/min & $161 \pm 11$ & $163 \pm 11$ & $160 \pm 11$ & $166 \pm 11 * \dagger$ \\
\hline$\% \mathrm{HR}_{\max }$ & $86 \pm 3$ & $87 \pm 4$ & $85 \pm 4$ & $88 \pm 4^{* \dagger}$ \\
\hline Rate of perceived exertion & $8.5 \pm 0.8$ & $8.8 \pm 0.8$ & $8.4 \pm 0.8$ & $8.7 \pm 1.1$ \\
\hline
\end{tabular}

Values are presented as means \pm SD. *Significantly different from pretraining; † significantly different from the control group at posttraining. 
Table 3. hs-cTnT concentrations after $60 \mathrm{~min}$ of high-intensity running pre- and posttraining

\begin{tabular}{|c|c|c|c|c|c|c|}
\hline \multirow[b]{3}{*}{ Preexercise } & \multicolumn{2}{|c|}{ Control Group $(n=18)$} & \multicolumn{2}{|c|}{ Exercise Group $(n=28)$} & \multirow{2}{*}{\multicolumn{2}{|c|}{$P$ Values by ANOVA }} \\
\hline & Pretraining & Posttraining & Pretraining & Posttraining & & \\
\hline & $3.0(3.0-8.1)$ & $3.2(3.0-7.5)$ & $3.6(3.0-16.2)$ & $5.1(3.0-16.8)$ & Time & $<0.0001$ \\
\hline Percentage of subjects exceeding the URL & 0 & 0 & 0 & 7 & & \\
\hline $5 \mathrm{~min}$ & $5.1(3.0-10.8)$ & $5.3(3.3-12.2)$ & $6.8(3.0-39.4)$ & $9.8(3.0-28.7)$ & Training & 0.003 \\
\hline Percentage of subjects exceeding the URL & 0 & 0 & 14 & 14 & & \\
\hline $1 \mathrm{~h}$ & $9.5(5.2-23.7)$ & $9.6(3.8-22.3)$ & $10.0(3.0-36.5)$ & $13.6(6.1-67.9)$ & Group & 0.073 \\
\hline Percentage of subjects exceeding the URL & 11 & 17 & 25 & 46 & & \\
\hline $\begin{array}{l}3 \mathrm{~h} \\
\text { Percentage of subjects exceeding the URL }\end{array}$ & $\begin{array}{c}14.2(9.7-57.2) \\
50\end{array}$ & $\begin{array}{c}16.6(8.4-49.8) \\
67\end{array}$ & $\begin{array}{c}16.1(4.9-140.7) \\
64\end{array}$ & $\begin{array}{c}26.3(6.6-171.0) \\
89\end{array}$ & Time $\times$ group & 0.512 \\
\hline $\begin{array}{l}6 \mathrm{~h} \\
\text { Percentage of subjects exceeding the URL }\end{array}$ & $\begin{array}{c}13.0(7.0-65.0) \\
44\end{array}$ & $13.4(5.7-41.2)(50)$ & $15.2(3.5-97.7)(54)$ & $\begin{array}{c}18.9(6.4-156.0) \\
79\end{array}$ & Training $\times$ group & 0.008 \\
\hline 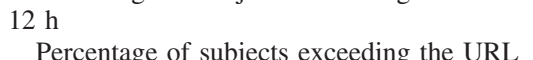 & $6.7(3.7-58.1)$ & $\begin{array}{c}8.3(4.0-24.7) \\
22\end{array}$ & $\begin{array}{c}9.2(3.0-39.1) \\
29\end{array}$ & $\begin{array}{c}11.0(4.6-68.5) \\
32\end{array}$ & Time $\times$ training & 0.123 \\
\hline $24 \mathrm{~h}$ & $4.3(3.0-33.2)$ & $4.9(3.0-12.5)$ & $6.3(3.0-19.3)$ & $6.7(3.0-36.2)$ & $\begin{array}{l}\text { Time } \times \text { training } \times \\
\text { group }\end{array}$ & 0.125 \\
\hline Percentage of subjects exceeding the URL & 11 & 0 & 7 & 11 & & \\
\hline
\end{tabular}

Data are presented as medians (ranges). Percentages of subjects with high-sensitivity cardiac troponin $\mathrm{T}$ (hs-cTnT) values exceeding the upper reference limit (URL) are also shown.

Impact of exercise training on NT-proBNP release. There was an increase in NT-proBNP from preexercise to $5 \mathrm{~min}, 1 \mathrm{~h}$, $3 \mathrm{~h}, 6 \mathrm{~h}, 12 \mathrm{~h}$, and $24 \mathrm{~h}$ postexercise $(P<0.0001$; Table 4$)$. In $15 \%$ of participants, NT-proBNP values exceeded the URL. Differences in the magnitude of peak data were accompanied by variable kinetics of NT-proBNP during recovery with the peak postexercise values observed at $0 \mathrm{~h}(38 \%), 1 \mathrm{~h}(13 \%), 3$ h (4\%), $6 \mathrm{~h}(10 \%), 12 \mathrm{~h}(26 \%)$, and $24 \mathrm{~h}(9 \%)$. Before the intervention, preexercise [median: $20.9 \mathrm{ng} / \mathrm{l}$ (range: 7.1-87.7 $\mathrm{ng} / \mathrm{l}$ ) in the control group and median: $20.4 \mathrm{ng} / \mathrm{l}$ (range: 8.4-123.4 ng/l) in the training group, $P=0.685$ ] and peak postexercise values [median: $40.6 \mathrm{ng} / \mathrm{l}$ (range: 16.4-169.3 $\mathrm{ng} / \mathrm{l}$ ) in the control group and median: $43.1 \mathrm{ng} / \mathrm{l}$ (range: $17.4-234.5 \mathrm{ng} / \mathrm{l}$ ) in the training group, $P=0.910$ ] of NTproBNP were similar between groups. The training program had no effect on pre- or postexercise NT-proBNP level $(P=$ $0.121)$.

In all tests, the peak postexercise level of NT-proBNP was strongly associated with preexercise concentration $(r>0.90)$. In the training group, NT-proBNP data were not associated with changes in 60-min time trial speed $(r=-0.061, P=$ $0.758)$ or mean HR $(r=0.015, P=0.940)$. Similar to hs-cTnT, preexercise and peak postexercise data for NTproBNP were strongly correlated in the two time trials undertaken, suggesting a high level of consistency in biomarker data (resting: $r=0.899, P<0.0001$, in the control group and $r=$ 0.694, $P<0.0001$, in the training group; peak postexercise: $r=$ $0.874, P<0.0001$, in the control group and $r=0.694, P<$ 0.0001 , in the training group).

\section{DISCUSSION}

The main findings of this study are that 1 ) a single 60-min bout of all-out running resulted in a significant increase in both hs-cTnT and NT-proBNP with substantial variability in individual peak postexercise data, 2) $14 \mathrm{wk}$ of endurance training resulted in higher pre- and postexercise values of hs-cTnT compared with baseline testing and the control group, 3) endurance training had no impact on postexercise NT-proBNP or on postexercise kinetics of either biomarker, and 4) preexercise and peak postexercise levels of both biomarkers were strongly correlated between both tests, a suggesting high reproducibility in the biomarker response to exercise.

$h s$-TnT and NT-proBNP release. This study confirms that the exercise-induced release of hs-cTnT and NT-proBNP is not exclusive to an ultraendurance effort. Between-study differences in exercise duration and/or the use of the new highsensitivity assay for cTnT could explain why the percentage of subjects with cTn values above the URL was greater in this study $(60 \mathrm{~min})$ than after a 30 -min run (33). The release of NT-proBNP is largely associated with exercise duration and/ volume $(30,31)$ with little influence exerted by exercise intensity $(12,30,31)$. A shorter, 60 -min run could explain a lower percentage of subjects exceeding the URL of NTproBNP in the present study.

Our results also confirm marked individual variability in both biomarkers $(16,38)$. The high individual variability in the peak postexercise response of hs-cTnT could not be explained by any control variable in this or another study (38). This suggests that some currently unknown physiological factors make participants more or less likely to release $\mathrm{cTn}$ in response to exercise.

Individual variability in the response to exercise of NTproBNP was strongly related to the variability in preexercise values $(11,12,23,31)$. Despite this, the present study observed a high degree of within-subject consistency in peak postexercise hs-cTnT release in both groups over their two trials, suggesting that hs-cTnT release is quite a robust phenomenon within any participant and that persists even after a training intervention that may alter the actual peak value of hs-cTnT. While this supports some recent work with hs-cTnT $(37,40)$, it contradicts other field work that proposed that the cT $(17,18$, 26) and NT-proBNP (37) response to exercise is random and not reproducible. The study-to-study differences are most likely due to methodological issues such as assay precision and environmental and exercise control as well as more frequent sampling. The high reproducibility in peak postexercise values of NT-proBNP also confirms previous work $(23,26)$. Ongoing work should determine the causes of the high-between subject variability in quantitative cT and NT-proBNP release. 

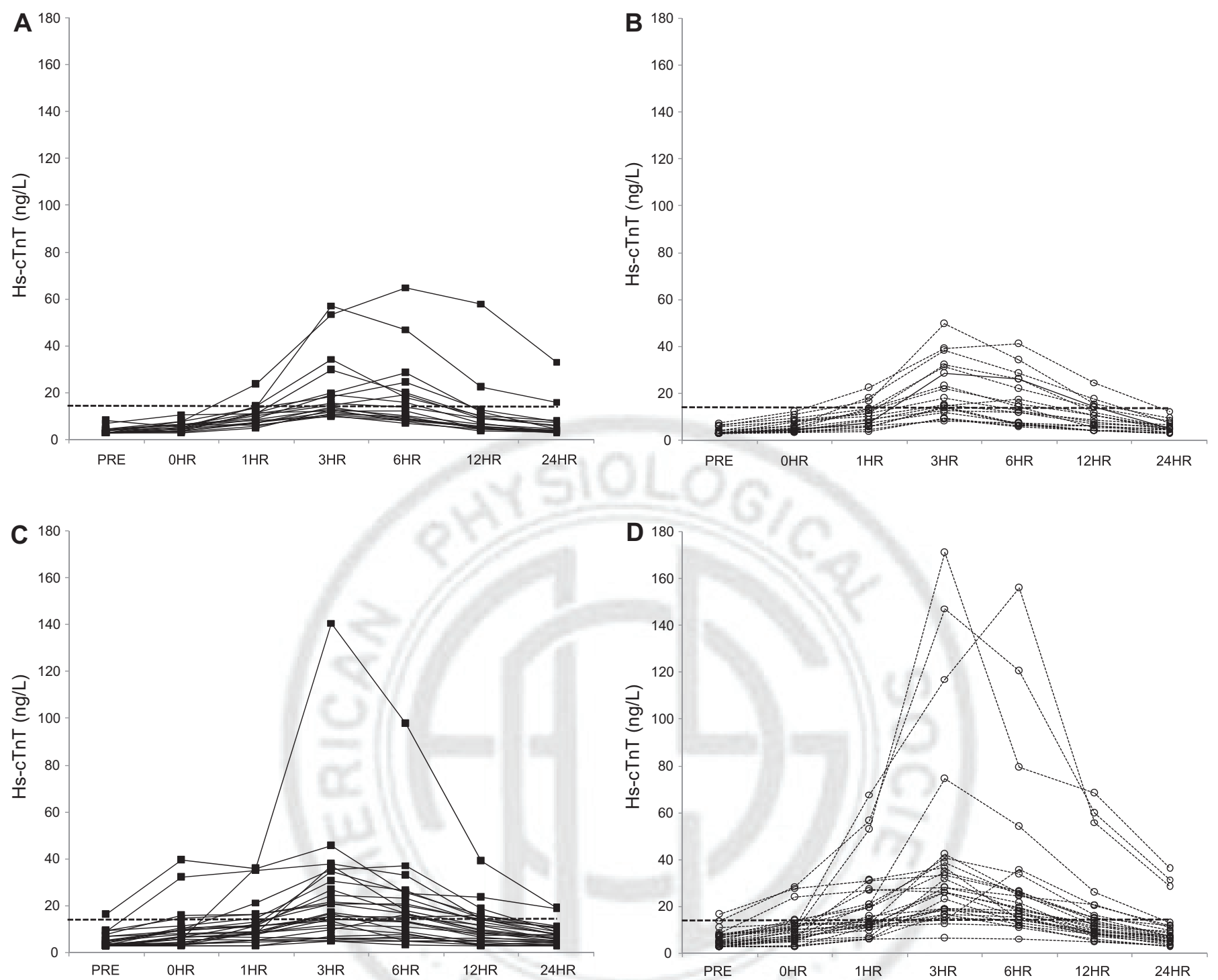

Fig. 2. Individual data points of high-sensitivity cardiac troponin $\mathrm{T}$ (hs-cTnT; in ng/l) in the control group at baseline $(A)$ and posttraining $(B)$ and in the training group at baseline $(C)$ and posttraining $(D)$ before exercise (pre) and $5 \mathrm{~min}, 1 \mathrm{~h}, 3 \mathrm{~h}, 6 \mathrm{~h}, 12 \mathrm{~h}$, and $24 \mathrm{~h}$ after a 60 -min maximal running trial. The horizontal dotted line is the upper reference limit (99th percentile) at $14 \mathrm{ng} / \mathrm{l}$.

Kinetics of hs-TnT and NT-proBNP release. This study provided a comprehensive analysis of individual postexercise kinetics for hs-cTnT and NT-proBNP. For hs-cTnT, most subjects showed a peak postexercise value at $3 \mathrm{~h}$, which is consistent with the only previous hs-cTnT study (38). Several studies $(6,21,37)$ have considered it sufficient to take a single blood sample $3-4 \mathrm{~h}$ postexercise to record the postexercise cTn peak. This viewpoint is only partially supported by the results of this study, as $15 \%$ of subjects obtained the peak postexercise value $6 \mathrm{~h}$ after the 60-min run. The discrepancy between studies might be attributed to differences in assay precision and the number of blood sample points after the start of exercise.

Importantly, kinetics data from the present study are somewhat different with those observed for cTn in acute myocardial infarction (36). At $24 \mathrm{~h}$ postexercise, all hs-cTnT values were close to preexercise levels. In addition, the increase in hs-cTnT occurred in the absence of clinical signs and symptoms. This suggests that postexercise hs-cTnT levels may reflect a phys- iological, rather than pathological, response to an exercise stimulus. The hypothesis that has been proposed is that endurance exercise causes an increase in membrane permeability due to the physiological stress placed on the cell, inducing a transient cytosolic leakage due to membrane damage, rather than cardiomyocyte necrosis (32), although this requires empirical support.

Postexercise kinetics of NT-proBNP have received less attention (38). Our data suggest that the kinetics for NTproBNP are more diverse than for hs-cTnT, with an incomplete recovery to baseline at $24 \mathrm{~h}$ postexercise. The elevation in NT-proBNP at $24 \mathrm{~h}$ could reflect a temporary reduction in kidney function and changes in cardiac function (38), but this requires further study.

Effect of exercise training on $h s-T n T$ and NT-proBNP values. Our main objective was to determine whether the hs-cTnT and NT-proBNP response to exercise is mediated by a change in training status. We observed higher baseline and 
Table 4. NT-proBNP concentrations after $60 \mathrm{~min}$ of high-intensity running pre-and posttraining

\begin{tabular}{|c|c|c|c|c|c|c|}
\hline \multirow[b]{3}{*}{ Preexercise } & \multicolumn{2}{|c|}{ Control Group $(n=18)$} & \multicolumn{2}{|c|}{ Exercise Group $(n=28)$} & \multirow{2}{*}{\multicolumn{2}{|c|}{$P$ Value by ANOVA }} \\
\hline & Pretraining & Posttraining & Pretraining & Posttraining & & \\
\hline & $20.9(7.1-87.7)$ & $18.7(6.0-121.0)$ & $20.4(8.4-123.4)$ & $21.1(6.7-73.0)$ & Time & $<0.0001$ \\
\hline Percentage of subjects exceeding the URL & 0 & 0 & 0 & 0 & & \\
\hline $5 \mathrm{~min}$ & $36.0(11.0-169.3)$ & $36.3(9.8-215.2)$ & $34.9(11.1-215.7)$ & $40.7(9.3-142.0)$ & Training & 0.299 \\
\hline Percentage of subjects exceeding the URL & 6 & 6 & 7 & 7 & & \\
\hline $1 \mathrm{~h}$ & $28.4(11.2-147.5)$ & $30.8(10.4-196.7)$ & $32.9(12.5-234.5)$ & $36.0(10.9-178.6)$ & Group & 0.896 \\
\hline Percentage of subjects exceeding the URL & 11 & 11 & 7 & 7 & & \\
\hline $3 \mathrm{~h}$ & $26.7(9.9-139.3)$ & $29.1(9.1-187.4)$ & $27.2(12.6-207.7)$ & $33.5(11.1-204.7)$ & Time $\times$ group & 0.431 \\
\hline Percentage of subjects exceeding the URL & 6 & 6 & 4 & 7 & & \\
\hline $6 \mathrm{~h}$ & $31.6(12.3-148.4)$ & $29.6(9.9-142.7)$ & $31.3(11.9-135.0)$ & $31.9(17.0-127.5)$ & Training $\times$ group & 0.121 \\
\hline Percentage of subjects exceeding the URL & 17 & 6 & 4 & 4 & & \\
\hline $12 \mathrm{~h}$ & $29.5(16.4-158.9)$ & $33.1(10.8-121.2)$ & $29.3(9.1-103.4)$ & $35.1(16.0-105.3)$ & Time $\times$ training & 0.207 \\
\hline Percentage of subjects exceeding the URL & 17 & 0 & 0 & 0 & & \\
\hline $24 \mathrm{~h}$ & $26.4(10.5-99.7)$ & $27.1(10.5-100.4)$ & $24.1(9.1-55.9)$ & $26.7(11.4-103.8)$ & $\begin{array}{l}\text { Time } \times \text { training } \times \\
\text { group }\end{array}$ & 0.540 \\
\hline Percentage of subjects exceeding the URL & 0 & 0 & 0 & 0 & & \\
\hline
\end{tabular}

Data are presented as medians (ranges). Percentages of subjects with $\mathrm{NH}_{2}$-terminal pro-brain natriuretic peptide (NT-proBNP) values exceeding the URL are also shown.

peak postexercise values for hs-cTnT after 14 wk of running training, which also differentiated this group from the control cohort. This supports some previous cross-sectional data from athletes of different training status (Legaz-Arrese et al., unpublished observations; and Ref. 24) but does contradict past field-based studies of runners with higher and lower selfreported training volumes (e.g., Ref. 20). The assay precision and method used to quantify the level of training may also be confounding factors in the relationship observed in previous studies. In the largest case series data in marathoners, Fortescue et al. (5) noted that the runners with less prior experience in marathon running were more likely to have cTnT increases. They also found no relationship between race time and the increase in cTnT, suggesting that the number of previous marathons may not be the most appropriate way to quantify the current level of training. Furthermore, the authors indicated no significant relationship between the release of cTnT and average training pace or average miles run per week during the last 3 mo. In the same direction, a multiple regression analysis demonstrated that marathon experience was a significant predictor of postmarathon hs-cTnT (19). Once again, the authors did not establish a relationship between marathon time and the release of hs-cTnT and did not gather other data on the level of training of the athletes. The association observed by Nie et al. (21) and Tian et al. (39) between the number of years of training and cTnT or cTnI release after a half-marathon in adolescent subjects was weak and could have been influenced by the maturity status of the adolescents. Moreover, in neither of these studies did the authors observe a relationship for other indicators of the level of training, such as weekly training distance. Finally, using a prospective study design, Mehta et al. (15) revealed that average miles run per week in the last $3 \mathrm{yr}$ (an indicator of previous training experience) was negatively associated with postmarathon cTnI release. No association, however, was observed for the current training status (miles run per week in the last $4 \mathrm{mo}$ ) or for race time.

Training resulted in a performance improvement in the 60-min running time trial at the same time as baseline and peak postexercise hs-cTnT were increased. It was, therefore, somewhat surprising to see that performance and hs-cTnT changes were not strongly associated. Whether this reflects a limited range of change in performance data or a lack of a systematic effect of training status change is difficult to determine. In field-based studies, where numerous factors are not controlled and performance and biomarker differences between groups may be more extensive, a closer association between training status and hs-cTnT release may be more apparent.

A number of theories could be proposed to explain the higher hs-cTnT after training. Although speculative, higher pre- and postexercise hs-cTnT values after training could be a consequence of an adaptive process occurring in the heart due to the exercise training stimulus. Heart size is associated with performance (14), and its adaptation is greater in less-trained subjects (13). Recent work from Saravia et al. (24) has suggested a link between higher levels of inflammation and increased cTn in faster marathon runners. Future work should evaluate these hypotheses in appropriate research designs.

We observed that training had no influence on the value of NT-proBNP or on the kinetics of either biomarker. Few studies have established the relationship between the level of training and exercise-induced release of NT-proBNP. Like Neilan et al. (20), Serrano-Ostáriz et al. (30) in road cyclists and Hermann et al. (8) in marathoners also observed a weak relationship between the level of training and release of NT-proBNP. This relationship disappeared when differences between athletes in the duration of effort were controlled. In other recent studies, the relationships have not been significant $(12,23,27,28,38)$.

Limitations, future research, and implications of this study. We selected previously untrained subjects because of the difficulty in establishing both control periods and a marked training change in athletes. For this reason, our work was limited to assessing the response of the release of cardiac biomarkers after an effort of relatively short duration (60 min). Our results, and their clinical impact, cannot be directly extrapolated to the effects of much more demanding training programs, such as those performed by elite athletes competing in marathons, road cycling, and triathlons. Many field-based studies, however, recruit amateur athletes who present with biomarker responses similar to those observed in the present study, and these athletes represent a much bigger and diverse 
proportion of mass-participation endurance events than elite athletes. The clinical importance, therefore, is more likely to be related to the amateur athlete presenting after an endurance event with a raised cardiac biomarker. Clearly, appropriate "work up" of any elevated hs-cTnT is important, but this must also recognize prior exercise as a key component.

The relationship between the exercise-induced release of cardiac biomarkers and the factors determinants of running performance (e.g., maximal $\mathrm{O}_{2}$ consumption) might be useful to evaluate high individual variability in biomarker release. Future work should also recruit a larger sample of female athletes and address the issue of whether the phase of the menstrual cycle could mediate biomarker release.

In conclusion, a 14-wk endurance running training program led to higher preexercise and peak postexercise values of hs-cTnT but did not change NT-proBNP or the kinetics of either biomarker. The change in hs-cTnT after training was not directly related to changes in performance or cardiovascular stress of a 60-min exercise stimulus after the intervention. The kinetics of hs-cTnT appearance suggest that the exerciseinduced release is a physiological process with no known clinical consequences. Clinicians should be aware that the release of cardiac biomarkers is not exclusive to long-term strenuous efforts, and values above the URL for hs-cTnT can be observed in most subjects.

\section{ACKNOWLEDGMENTS}

The authors thank all participants for participation in this study.

\section{GRANTS}

This work was supported by the DEP 2010-16767 grants from the National Plan for Research, Development and Innovation $(\mathrm{R}+\mathrm{D}+\mathrm{i}) \mathrm{MICINN}$.

\section{DISCLOSURES}

No conflicts of interest, financial or otherwise, are declared by the author(s).

\section{AUTHOR CONTRIBUTIONS}

Author contributions: A.L.-A., K.P.G., and J.R.-M. conception and design of research; A.L.-A., K.P.G., and J.R.-M. approved final version of manuscript; I.L.-L., J.J.P.-L., C.M.-P., E.S.-O., and P.R.-M. analyzed data; I.L.-L., J.J.P.L., C.M.-P., P.R.-M., and D.M.-U. interpreted results of experiments; K.P.G., P.R.-M., and D.M.-U. edited and revised manuscript; J.J.P.-L., C.M.-P., E.S.-O., and P.R.-M. performed experiments; E.S.-O. drafted manuscript D.M.-U. prepared figures.

\section{REFERENCES}

1. Borg E, Kaijser L. A comparison between three rating scales for perceived exertion and two different work tests. Scand J Med Sci Sports 16 57-69, 2006.

2. Collinson PO, Barnes SC, Gaze DC, Galasko G, Lahiri A, Senior R. Analytical performance of the $\mathrm{N}$ terminal pro B type natriuretic peptide (NT-proBNP) assay on the Elecsys 1010 and 2010 analysers. Eur J Heart Fail 6: 365-368, 2004.

3. Craig CL, Marshall AL, Sjöström M, Bauman AE, Booth ML, Ainsworth BE, Pratt M, Ekelund U, Yngve A, Sallis JF, Oja P. International physical activity questionnaire: 12-country reliability and validity. Med Sci Sports Exerc 35: 1381-1395, 2003.

4. Eijsvogels TM, Hoogerwerf MD, Maessen MF, Seeger JP, George KP, Hopman MT, Thijssen DH. Predictors of cardiac troponin release after a marathon. J Sci Med Sport 18: 88-92, 2015.

5. Fortescue EB, Shin AY, Greenes DS, Mannix RC, Agarwal S, Feldman BJ, Shah MI, Rifai N, Landzberg MJ, Newburger JW, Almond CS. Cardiac troponin increases among runners in the Boston Marathon. Ann Emerg Med 49: 137-143, 2007.

6. Fu F, Nie J, George K, Tom TK, Lin H, Shi Q. Impact of 21-km run on cardiac biomarkers in adolescent runners. J Exerc Sci Fit 8: 61-66, 2010.
7. Giannitsis E, Kurz K, Hallermayer K, Jarausch J, Jaffe AS, Katus HA. Analytical validation of a high-sensitivity cardiac troponin $\mathrm{T}$ assay. Clin Chem 56: 254-261, 2010.

8. Herrmann M, Scharhag J, Miclea M, Urhausen A, Herrmann W, Kindermann W. Post-race kinetics of cardiac troponin $\mathrm{T}$ and $\mathrm{I}$ and $\mathrm{N}$-terminal pro-brain natriuretic peptide in marathon runners. Clin Chem 49: 831-834, 2003

9. Hubble KM, Fatovich DM, Grasko JM, Vasikaran SD. Cardiac troponin increases among marathon runners in the Perth Marathon: the Troponin in Marathons (TRIM) study. Med J Aust 190: 91-93, 2009.

10. Issurin VB. New horizons for the methodology and physiology of training periodization. Sports Med. 40: 189-206, 2010.

11. Klinkenberg LJ, Res PT, van Loon LJ, van Dieijen-Visser MP, Meex SJ. Strong link between basal and exercise-induced cardiac troponin T levels: do both reflect risk? Int J Cardiol 158: 129-131, 2012.

12. Legaz-Arrese A, George K, Carranza-García LE, Munguía-Izquierdo D, Moros-García T, Serrano-Ostáriz E. The impact of exercise intensity on the release of cardiac biomarkers in marathon runners. Eur J Appl Physiol 111: 2961-2967, 2011.

13. Legaz-Arrese A, González-Carretero M, Lacambra-Blasco I. Adaptation of left ventricular morphology to long-term training in sprint- and endurance-trained elite runners. Eur J Appl Physiol 96: 740-746, 2006.

14. Legaz Arrese A, Serrano Ostáriz E, González Carretero M, Lacambra Blasco I. Echocardiography to measure fitness of elite runners. J Am Soc Echocardiogr 18: 419-426, 2005.

15. Mehta R, Gaze D, Mohan S, Williams KL, Sprung V, George K, Jeffries R, Hudson Z, Perry M, Shave R. Post-exercise cardiac troponin release is related to exercise training history. Int J Sports Med 33: 333-337, 2012.

16. Middleton N, George K, Whyte G, Gaze D, Collinson P, Shave R. Cardiac troponin $\mathrm{T}$ release is stimulated by endurance exercise in healthy humans. J Am Coll Cardiol 52: 1813-1814, 2008.

17. Middleton N, Shave R, George K, Whyte G, Hart E, Oxborough D, Forster J, Gaze D. Altered left ventricular diastolic filling following a marathon is a reproducible phenomenon. Int J Cardiol 122: 87-89, 2007.

18. Middleton N, Shave R, George K, Whyte G, Simpson R, FloridaJames G, Gaze D. Impact of repeated prolonged exercise bouts on cardiac function and biomarkers. Med Sci Sports Exerc 39: 83-90, 2007.

19. Mingels A, Jacobs L, Michielsen E, Swaanenburg J, Wodzig W, van Dieijen-Visser M. Reference population and marathon runner sera assessed by highly sensitive cardiac troponin $\mathrm{T}$ and commercial cardiac troponin T and I assays. Clin Chem 55: 101-108, 2009.

20. Neilan TG, Januzzi JL, Lee-Lewandrowski E, Ton-Nu TT, Yoerger DM, Jassal DS, Lewandrowski KB, Siegel AJ, Marshall JE, Douglas PS, Lawlor D, Picard MH, Wood MJ. Myocardial injury and ventricular dysfunction related to training levels among nonelite participants in the Boston marathon. Circulation 114: 2325-2333, 2006.

21. Nie J, George KP, Tong TK, Gaze D, Tian Y, Lin H, Shi Q. The influence of a half-marathon race upon cardiac troponin $\mathrm{T}$ release in adolescent runners. Curr Med Chem 18: 3452-3456, 2011.

22. Rodríguez FA. Versión española del cuestionario de aptitud para la actividad física (C-AAF/rPAR-Q). Arch Med Deporte 51: 63-68, 1996.

23. Sahlén A, Winter R, Lind B, Jacobsen PH, Ståhlberg M, Marklund T, Fux T, Svensson J, Braunschweig F. Magnitude, reproducibility, and association with baseline cardiac function of cardiac biomarker release in long-distance runners aged $>$ or $=55$ years. Am J Cardiol 102: 218-222, 2008 .

24. Saravia SG, Knebel F, Schroeckh S, Ziebig R, Lun A, Weimann A, Haberland A, Borges AC, Schimke I. Cardiac troponin T release and inflammation demonstrated in marathon runners. Clin Lab 56: 51-58, 2010.

25. Scharhag J, Herrmann M, Urhausen A, Haschke M, Herrmann W, Kindermann W. Independent elevations of N-terminal pro-brain natriuretic peptide and cardiac troponins in endurance athletes after prolonged strenuous exercise. Am Heart J 150: 1128-1134, 2005.

26. Scharhag J, Urhausen A, Schneider G, Herrmann M, Schumacher K, Haschke M, Krieg A, Meyer T, Herrmann W, Kindermann W. Reproducibility and clinical significance of exercise-induced increases in cardiac troponins and N-terminal pro brain natriuretic peptide in endurance athletes. Eur J Cardiovasc Prev Rehabil 13: 388-397, 2006.

27. Scherr J, Braun S, Schuster T, Hartmann C, Moehlenkamp S, Wolfarth B, Pressler A, Halle M. 72-h kinetics of high-sensitive troponin $\mathrm{T}$ and inflammatory markers after marathon. Med Sci Sports Exerc 43: $1819-1827,2011$ 
28. Scott JM, Esch BT, Shave R, Warburton DE, Gaze D, George K. Cardiovascular consequences of completing a 160-km ultramarathon. Med Sci Sports Exerc 41: 26-34, 2009.

29. Seiler $\mathbf{S}$. What is best practice for training intensity and duration distribution in endurance athletes? Int J Sports Physiol Perform 5: 276-291, 2010.

30. Serrano-Ostáriz E, Legaz-Arrese A, Terreros-Blanco JL, López-Ramón M, Cremades-Arroyos D, Carranza-García LE, Izquierdo-Alvarez S, Bocos-Terraz P. Cardiac biomarkers and exercise duration and intensity during a cycle-touring event. Clin J Sport Med 19: 293-299, 2009.

31. Serrano-Ostáriz E, Terreros-Blanco JL, Legaz-Arrese A, George $\mathbf{K}$, Shave R, Bocos-Terraz P, Izquierdo-Álvarez S, Bancalero JL, Echavarri JM, Quilez J, Aragonés MT, Carranza-García LE. The impact of exercise duration and intensity on the release of cardiac biomarkers. Scand J Med Sci Sports 21: 244-249, 2011.

32. Shave R, Oxborough D. Exercise-induced cardiac injury: evidence from novel imaging techniques and highly sensitive cardiac troponin assays. Prog Cardiovasc Dis 54: 407-415, 2012.

33. Shave R, Ross P, Low D, George K, Gaze D. Cardiac troponin I is released following high-intensity short-duration exercise in healthy humans. Int J Cardiol 145: 337-339, 2010.

34. Silver MA, Maisel A, Yancy CW, McCullough PA, Burnett JC Jr, Francis GS, Mehra MR, Peacock WF 4th, Fonarow G, Gibler WB, Morrow DA, Hollander J; BNP Consensus Panel. BNP Consensus
Panel 2004: a clinical approach for the diagnostic, prognostic, screening, treatment monitoring, and therapeutic roles of natriuretic peptides in cardiovascular diseases. Congest Heart Fail 10: 1-30, 2004.

35. Thomas S, Reading J, Shephard RJ. Revision of the Physical Activity Readiness Questionnaire (PAR-Q). Can J Sport Sci 17: 338-345, 1992.

36. Thygesen K, Alpert JS, Jaffe AS, Simoons ML, Chaitman BR, White HD. Writing group on behalf of the joint ESC/ACCF/AHA/WHF task force for the universal definition of myocardial infarction. Third universal definition of myocardial infarction. J Am Coll Cardiol 60: 1581-1598, 2012.

37. Tian Y, Nie J, George KP, Huang C. Reproducibility of cardiac biomarkers response to prolonged treadmill exercise. Biomarkers 19: 114-120, 2014

38. Tian Y, Nie J, Huang C, George KP. The kinetics of highly sensitive cardiac troponin $\mathrm{T}$ release after prolonged treadmill exercise in adolescent and adult athletes. J Appl Physiol (1985) 113: 418-425, 2012.

39. Tian Y, Nie J, Tong TK, Cao J, Gao Q, Man J, Shi Q, Liu W. Changes in serum cardiac troponins following a $21-\mathrm{km}$ run in junior male runners. J Sports Med Phys Fitness 46: 481-488, 2006.

40. Wedin JO, Henriksson AE. Postgame elevation of cardiac markers among elite floorball players. Scand J Med Sci Sports; doi:10.1111/ sms.12304.

41. Yuhasz MS. Physical Fitness Manual. London, ON, Canada: Univ. of Western Ontario, 1974 